\title{
Effect of dietary antioxidant and increasing corn oil inclusion on milk fat yield and fatty acid composition in dairy cattle
}

\author{
J. P. Boerman, C. L. Preseault, and A. L. Lock ${ }^{1}$ \\ Department of Animal Science, Michigan State University, East Lansing 48824
}

ABSTRACT

The objective of this study was to examine the effect of a dietary synthetic antioxidant on feed intake, yields of milk and milk components and milk fatty acids (FA), in combination with increasing concentrations of dietary corn oil to provide increasing rumen unsaturated fatty acid load (RUFAL) challenges. Twenty-six Holstein cows $(177 \pm 57 \mathrm{~d}$ in milk; mean \pm standard deviation) were assigned to treatment in a randomized complete block design. Treatments were a control diet $(\mathrm{CON} ; \mathrm{n}=13 \mathrm{cows})$ or the same diet supplemented with a synthetic antioxidant (AOX; $6.1 \mathrm{~g} / \mathrm{d}$; dry blend of ethoxyquin and propyl gallate, Novus International Inc., St. Charles, MO; $\mathrm{n}=13$ cows). In period 1 (21 d), no supplemental corn oil was fed; in periods 2,3 , and 4 (14 d each), corn oil was supplemented at 0.7, 1.4 , and $2.8 \%$ of the diet [dry matter (DM) basis] to incrementally increase RUFAL. For all variables measured, no significant interactions were detected between treatment and period, indicating no differences between the CON and AOX treatments at all levels of oil inclusion. Intake of DM was lower for AOX compared with CON but AOX had no effect on milk yield or milk fat concentration and yield. Milk protein yield and feed efficiency (energy-corrected milk/DM intake) tended to be greater for $\mathrm{AOX}$ compared with $\mathrm{CON}$. Increasing dietary corn oil concentration (RUFAL) decreased DM intake, milk yield, milk fat concentration and yield, and feed efficiency. The AOX treatment increased the concentration and yield of 16-carbon milk FA, with no effect on de novo ( $<16$ carbon) or preformed $(>16$ carbon) milk FA. Milk FA concentration of trans-10 C18:1, trans-10,cis-12 C18:2, and trans-9,cis-11 C18:2 were unaffected by AOX but increased with increasing RUFAL. In conclusion, supplementation with AOX did not overcome the dietary-induced milk fat depression caused by increased RUFAL.

Key words: antioxidant, dairy cow, milk fat, unsaturated fatty acid

Received November 9, 2013

Accepted September 5, 2014.

${ }^{1}$ Corresponding author: allock@msu.edu
INTRODUCTION

Over the last decade, significant advances have aided our understanding of the interrelationship between rumen lipid metabolism and milk fat synthesis. The available evidence indicates that milk fat depression (MFD) is caused by altered rumen fermentation resulting in changes in rumen biohydrogenation of unsaturated FA and the passage of specific intermediates of biohydrogenation out of the rumen that subsequently reduce milk fat synthesis in the mammary gland by altering expression of genes involved in fat synthesis (Bauman et al., 2011). Milk fat is produced by 2 mechanisms, either the incorporation of preformed FA $\geq 16$ carbons in length or the production of short- and medium-chain FA $\leq 16$ carbons in length (de novo synthesis) in the mammary gland (Bauman and Davis, 1974). Several intermediates produced during the biohydrogenation of unsaturated FA have been shown to directly inhibit milk fat synthesis: trans-10,cis-12 C18:2 (Baumgard et al., 2001), cis-10,trans-12 C18:2 (Sæbø et al., 2005), and trans-9,cis-11 C18:2 (Perfield et al., 2007).

Because dietary unsaturated FA are toxic to rumen bacteria (Maia et al., 2007), increasing the rumen unsaturated FA load (RUFAL) of dairy cows may alter rates and pathways of biohydrogenation, thereby potentially increasing the risk of MFD. Previous work has determined the key changes in biohydrogenation pathways and profiles that are indicative of the alterations that lead to MFD (Bauman et al., 2011). Much of this focus has been on trans C18:1 isomers, particularly trans-10 C18:1. Although trans-10 C18:1 is not a causative factor of MFD, as demonstrated by abomasal infusion of the pure FA (Lock et al., 2007), it is relatively easy to analyze compared with $\mathrm{C} 18: 2$ biohydrogenation intermediates that are present in much lower concentrations in milk fat, and there is a robust relationship between its production in the rumen and milk fat synthesis (e.g., Loor et al., 2005; Shingfield et al., 2006). Thus, trans-10 C18:1 can serve as a surrogate marker for the type of alterations in rumen biohydrogenation that characterize diet-induced MFD.

Results from previous studies have suggested that high levels of vitamin E ( $\alpha$-tocopheryl acetate, 6,000 
to $12,000 \mathrm{IU} / \mathrm{d}$ ) may have the potential to prevent the "trans-10 shift" during biohydrogenation, thus reducing the risk of MFD, although in some cases the objectives of individual studies did not focus on rumen biohydrogenation and milk fat yield (Charmley and Nicholson, 1994; Focant et al., 1998; Pottier et al., 2006). However, more recent results from studies designed to directly examine the effect of vitamin $\mathrm{E}$ supplementation on overcoming MFD offer no support for a role of vitamin $\mathrm{E}$ in mitigating MFD (O'DonnellMegaro et al., 2012; Zened et al., 2012). Although results are inconsistent, the potential for antioxidants to prevent the trans-10 shift during biohydrogenation warrant further examination. An improved understanding of potential situations where antioxidants affect biohydrogenation may allow for more flexibility in ration formulation by allowing inclusion of ingredients with high or variable unsaturated FA content while reducing the risk of MFD.

Several studies have reported benefits of commercially available synthetic antioxidants on the performance and health of lactating dairy cattle. For example, Vázquez-Añón et al. (2008) reported improved milk fat yield when a synthetic antioxidant was supplemented with either $2 \%$ oxidized or fresh soybean oil, and Wang et al. (2010) observed a tendency for increased fatcorrected milk yield during early lactation. However, He and Armentano (2011) reported no effect of a synthetic antioxidant on milk fat yield for diets containing $5 \%$ additional unsaturated oils. In a recent study, we observed a trend for increased milk fat concentration when a synthetic antioxidant was supplemented in a diet containing dried distillers grains that contained a considerable amount of unsaturated FA (Boerman et al., 2014). In our previous study, the synthetic antioxidant was supplemented at the same time as the added unsaturated FA. Based on these results, we hypothesized that the timing of the antioxidant inclusion, relative to an unsaturated FA challenge, may affect the magnitude of the response. Therefore, our objective in the current study was to evaluate production responses to a synthetic antioxidant combined with increasing concentrations of dietary corn oil to provide increasing RUFAL challenges.

\section{MATERIALS AND METHODS}

\section{Design and Treatments}

Experimental procedures were approved by the Institutional Animal Care and Use Committee at Michigan State University (East Lansing). Twenty-six Holstein cows averaging $177 \pm 57$ DIM (mean \pm SD) from the Michigan State University Dairy Field Laboratory were used in a randomized complete block design with a preliminary period (14 d), a treatment period (21 d), and 3 RUFAL challenge periods (14 d each). During the preliminary period, all cows were fed a common diet to obtain baseline production data. For the treatment period, cows were blocked by $3.5 \%$ FCM and then randomly assigned to 1 of 2 diets: a control diet $(\mathbf{C O N} ; \mathrm{n}=$ 13 cows) or the control diet supplemented with a novel blend of synthetic antioxidants (AOX; Agrado Ultra, a dry blend of ethoxyquin and propyl gallate; Novus International Inc., St. Charles, MO; $\mathrm{n}=13$ cows). The synthetic antioxidant blend in the AOX treatment was top-dressed daily at a rate of $6.1 \mathrm{~g} / \mathrm{d}$. Cows remained in their respective treatment group (CON or AOX) for the remainder of the experiment, including challenge periods. During RUFAL challenge periods, corn oil was added $(0.7,1.4$, and $2.8 \%$ of diet DM, respectively) to incrementally increase RUFAL concentration. Corn oil replaced soyhulls in the diet.

The ingredients and nutrient composition of experimental diets are shown in Table 1. Diets were formulated to contain $28 \% \mathrm{NDF}, 28 \%$ starch, and $17 \% \mathrm{CP}$, and mineral and vitamins were formulated according to NRC (2001) recommendations. Dry matter concentration was determined twice weekly for forages, and diets were adjusted when necessary.

\section{Data and Sample Collection}

Throughout the experiment, cows were housed in individual tiestalls and milked twice daily (0400 and 1500 h). Access to feed was blocked from 0800 to $1000 \mathrm{~h}$ to allow for collection of orts and provision of feed. Cows were fed $115 \%$ of expected intake at $1000 \mathrm{~h}$ daily. Water was available ad libitum in each stall, and stalls were bedded with sawdust and cleaned twice daily. Feed intake and milk yield were determined daily throughout the study. Samples and data were collected on d 12 to 14 of the preliminary period, d 17 to 21 of the treatment period, and d 12 to 14 of each RUFAL challenge period. Samples of all diet ingredients $(0.5 \mathrm{~kg})$ and orts from each cow (12.5\%) were collected daily, stored at $-20^{\circ} \mathrm{C}$, and composited by period for analysis. Milk yield was recorded and 2 milk samples were collected at each milking for determination of milk composition. One milk sample was collected in a sealed tube and stored with preservative (bronopol tablet; D\&F Control Systems, San Ramon, CA) at $4^{\circ} \mathrm{C}$ for milk component analysis. The other milk sample was stored without preservative at $-20^{\circ} \mathrm{C}$ until analyzed for $\mathrm{FA}$ composition. Cows were weighed on the last $2 \mathrm{~d}$ of each period. Three trained investigators determined BCS on a 5-point scale (in 0.25-point increments; Wildman et al., 1982) on the last day of each period. 
Table 1. Ingredients and nutrient composition (\% of DM, unless otherwise noted) of experimental diets supplemented with increasing concentrations of corn oil ${ }^{1}$

\begin{tabular}{|c|c|c|c|c|}
\hline \multirow[b]{2}{*}{ Item } & \multicolumn{4}{|c|}{ Inclusion of corn oil ${ }^{2}$} \\
\hline & $0.0 \%$ & $0.7 \%$ & $1.4 \%$ & $2.8 \%$ \\
\hline \multicolumn{5}{|l|}{ Ingredient } \\
\hline Corn silage & 30.5 & 31.4 & 31.7 & 32.2 \\
\hline Alfalfa silage & 10.8 & 8.4 & 8.6 & 8.3 \\
\hline Alfalfa hay & 8.2 & 8.3 & 8.1 & 7.7 \\
\hline Wheat straw & 1.0 & 1.0 & 1.0 & 1.0 \\
\hline Ground corn & 15.6 & 16.1 & 16.0 & 16.2 \\
\hline High-moisture corn & 3.6 & 3.8 & 4.0 & 3.9 \\
\hline Soybean meal & 14.1 & 14.4 & 14.3 & 14.2 \\
\hline Soyhulls & 4.6 & 3.9 & 3.1 & 1.7 \\
\hline Cottonseed with lint & 3.3 & 3.4 & 3.4 & 3.5 \\
\hline Corn oil & 0.0 & 0.7 & 1.4 & 2.8 \\
\hline Vitamin and mineral $\operatorname{mix}^{3}$ & 8.4 & 8.6 & 8.5 & 8.5 \\
\hline \multicolumn{5}{|l|}{ Nutrient composition } \\
\hline DM, $\%$ & 54.7 & 53.7 & 52.4 & 53.9 \\
\hline NDF & 29.3 & 27.9 & 29.9 & 29.0 \\
\hline Forage NDF & 21.6 & 20.6 & 22.9 & 23.2 \\
\hline Starch & 27.6 & 29.4 & 27.9 & 27.4 \\
\hline $\mathrm{CP}$ & 17.9 & 17.7 & 17.5 & 16.8 \\
\hline FA & 2.7 & 3.4 & 3.7 & 5.3 \\
\hline
\end{tabular}

${ }^{1}$ Cows received either a control diet $(\mathrm{n}=13 \mathrm{cows})$ or the same diet supplemented with $6.1 \mathrm{~g} / \mathrm{d}$ of a synthetic antioxidant (dry blend of ethoxyquin and propyl gallate, Novus International Inc., St. Charles, MO; $\mathrm{n}=13$ cows).

${ }^{2}$ Corn oil inclusion rate as $\%$ of diet DM.

${ }^{3}$ Vitamin and mineral mix contained $58.3 \%$ dry ground shell corn, $12.3 \%$ limestone, $7.9 \%$ sodium bicarbonate, $6.8 \%$ dicalcium phosphate, $3.2 \%$ urea, $3.2 \%$ magnesium, $3.2 \%$ tallow, $3.0 \%$ white salt, and $<1 \%$ of each of the following: trace minerals, biotin, vitamin $\mathrm{E}$, vitamin $\mathrm{A}$, vitamin $\mathrm{D}$, and selenium.

\section{Sample Analysis}

Feed and orts samples were dried in a $55^{\circ} \mathrm{C}$ oven for $3 \mathrm{~d}$ and used to calculate DM concentration and DMI. Dried feed ingredients from each period were ground in a Wiley mill (1-mm screen; Arthur H. Thomas, Philadelphia, PA), and analyzed for NDF with heat-stable $\alpha$-amylase and sodium sulfite (Van Soest et al., 1991), CP (AOAC International, 2000; method 990.03), and starch (Hall, 2009) by Cumberland Valley Analytical Services Inc. (Hagerstown, MD). Feed ingredients were analyzed for FA content using a one-step transesterification method previously described by Lock et al. (2013). Individual milk samples were analyzed for fat (filter $\mathrm{B})$, true protein, and lactose concentration by midinfrared spectroscopy (AOAC, 1990; method 972.160) by the Michigan Herd Improvement Association (Universal Lab Services, Lansing, MI). Yields of 3.5\% FCM, ECM, and milk components were calculated using milk yield and component concentrations for each milking, summed for a daily total, and averaged for each collection period.

Milk samples used for analysis of FA composition were composited each period based on milk fat yield. Lipids were extracted, FAME formed, and FAME quantified by GLC as described previously (Lock et al., 2013). In brief, total lipids from milk fat were extracted using $n$ hexane:isopropanol (3:2, vol/vol) and FAME prepared using $0.5 \mathrm{M}$ sodium methoxide solution in methanol. Fatty acid composition covering $\sim 70 \mathrm{FA}$ in the range from C4:0 to C24:0 was determined by a GC-2010 Plus gas chromatograph (Shimadzu, Kyoto, Japan) with a split injector (1:100 split ratio) and a flame-ionization detector using a CP-Sil 88 WCOT fused-silica column $(100 \mathrm{~m} \times 0.25 \mathrm{~mm}$ i.d. $\times 0.2 \mu \mathrm{m}$ film thickness; Varian Inc., Lake Forest, CA). Individual FAME were identified by comparison of retention times with known authentic FAME standards (GLC reference standard 463, GLC reference standard 481-B, and conjugated octadecadienoic mixture \#UC-59-M from Nu-Chek Prep Inc., Elysian, MN; Supelco 37 component FAME mix, cis/trans FAME mix, bacterial acid methyl ester mix, and PUFA No. 3 mix from Supelco Inc., Bellefonte, PA) and published chromatograms (Tyburczy et al., 2012). Short-chain FAME were corrected for mass discrepancy using the response factors published by Ulberth and Schrammel (1995). Yields of individual FA (g/d) in milk fat were calculated by using milk fat yield and FA concentration to determine yield on a mass basis using the molecular weight of each FA while correcting for glycerol content and other milk lipid classes (Piantoni et al., 2013). 


\section{Statistical Analysis}

Data were analyzed using the GLIMMIX procedure of SAS with a Kenward Rogers adjustment for denominator degrees of freedom (version 9.2, SAS Institute Inc., Cary, NC). Preliminary measurements for production parameters and milk FA were used as a covariate to adjust for differences at the beginning of the trial. The model contained the random effect of cow nested within treatment $(\mathrm{CON}$ or $\mathrm{AOX})$ and the fixed effects of treatment (CON or AOX), period (corn oil inclusion, $0.0,0.7,1.4$, or $2.8 \% \mathrm{DM})$, their interaction, and the respective covariate. Least squares means for the interaction of treatment and period (corn oil inclusion) are reported; significant differences for the main effect of treatment (AOX vs. CON) and the interaction between treatment and period (corn oil inclusion) were declared at $P \leq 0.05$ and tendency was declared at $P \leq 0.10$. The experimental design did not allow us to separate the effect of corn oil inclusion $(0.0,0.7,1.4$, and $2.8 \%$ $\mathrm{DM})$ and period and therefore they are confounded.

\section{RESULTS}

Total dietary FA were 2.7, 3.4, 3.7, and $5.3 \%$ of diet DM for the $0.0,0.7,1.4$, and $2.8 \%$ corn oil diets, respectively (Table 1). The FA composition was similar for all diets, with most FA contributing to RUFAL (Table 2). As expected, we observed an increase in RUFAL intake $(\mathrm{g} / \mathrm{d})$ because the profile remained similar (Table 2) and intake of total FA increased.

Production responses to dietary treatments with increasing dietary corn oil concentrations are reported in Table 3. For all variables measured, we detected no significant interactions between treatment and period; therefore, the main effects of CON versus AOX will be described. We observed no effect of AOX on the yields of milk and milk fat or the concentration of milk components across treatments and all challenge periods $(P>0.10)$. However, we did observe a trend for AOX to increase milk protein yield $(P=0.07)$. Dry matter intake was lower for AOX than CON $(P=0.05)$, with feed efficiency tending to be greater for AOX-fed cows $(P=0.06)$.

Concentrations and yields of individual FA in milk fat are shown in Tables 4 and 5, respectively. We observed minimal effects of AOX on any FA, with AOX only slightly increasing the concentration of C16:0 in milk fat $(P=0.003)$ and reducing concentrations of cis9,cis-12 C18:2 and cis-9,cis-12,cis-15 C18:3 $(P=0.01$ and $P=0.004$, respectively). Similarly, we observed only minimal effects of AOX on the yield of individual milk FA, with AOX increasing the yield of 16:0 and cis-9 16:1 $(P=0.03$ and 0.002 , respectively; Table 5). However, AOX had no effect on the yield of de novo $(<16$ carbon) or preformed ( $>16$ carbon) milk FA. Increasing dietary corn oil concentration across treatment periods affected the concentrations and yields of all individual milk FA. Specific CLA isomers (trans9,cis-11 C18:2 and trans-10,cis-12 C18:2) that have been linked to MFD also increased with additional corn oil across treatment periods. However, we observed no significant interactions between treatment and period, indicating no differences between $\mathrm{CON}$ and AOX treatments on either of these 2 MFD-inducing CLA isomers or trans-10 C18:1 $(P>0.46)$.

\section{DISCUSSION}

The potential for antioxidants to alleviate the negative effects of MFD by maintaining normal rumen biohydrogenation has stimulated research on their efficacy

Table 2. Concentration of FA of experimental diets supplemented with increasing concentrations of corn oil ${ }^{1}$

\begin{tabular}{|c|c|c|c|c|}
\hline \multirow[b]{2}{*}{$\mathrm{FA}, \mathrm{g} / 100 \mathrm{~g}$ of total FA } & \multicolumn{4}{|c|}{ Inclusion of corn oil ${ }^{2}$} \\
\hline & $0.0 \%$ & $0.7 \%$ & $1.4 \%$ & $2.8 \%$ \\
\hline $14: 0$ & 0.6 & 0.6 & 0.7 & 0.6 \\
\hline $16: 0$ & 16.9 & 16.1 & 16.8 & 15.8 \\
\hline $18: 0$ & 3.5 & 3.3 & 3.3 & 3.0 \\
\hline $18: 1$ cis-9 & 19.5 & 19.9 & 20.8 & 21.5 \\
\hline $18: 2$ cis -9, cis -12 & 43.9 & 44.1 & 42.0 & 45.7 \\
\hline $18: 3$ cis- 9, cis- 12, cis- 15 & 9.3 & 8.7 & 7.8 & 6.5 \\
\hline $22: 0$ & 0.6 & 0.6 & 0.6 & 0.6 \\
\hline $24: 0$ & 0.5 & 0.5 & 0.6 & 0.5 \\
\hline$\Sigma$ Others & 5.1 & 6.2 & 7.5 & 5.8 \\
\hline$\Sigma \mathrm{SFA}$ & 22.5 & 21.5 & 22.5 & 20.9 \\
\hline$\Sigma \mathrm{RUFAL}^{3}$ & 72.7 & 72.7 & 70.6 & 73.7 \\
\hline
\end{tabular}


Table 3. Dry matter intake, milk production and composition, feed efficiency, BW, and BCS for cows fed treatment diets ${ }^{1}$

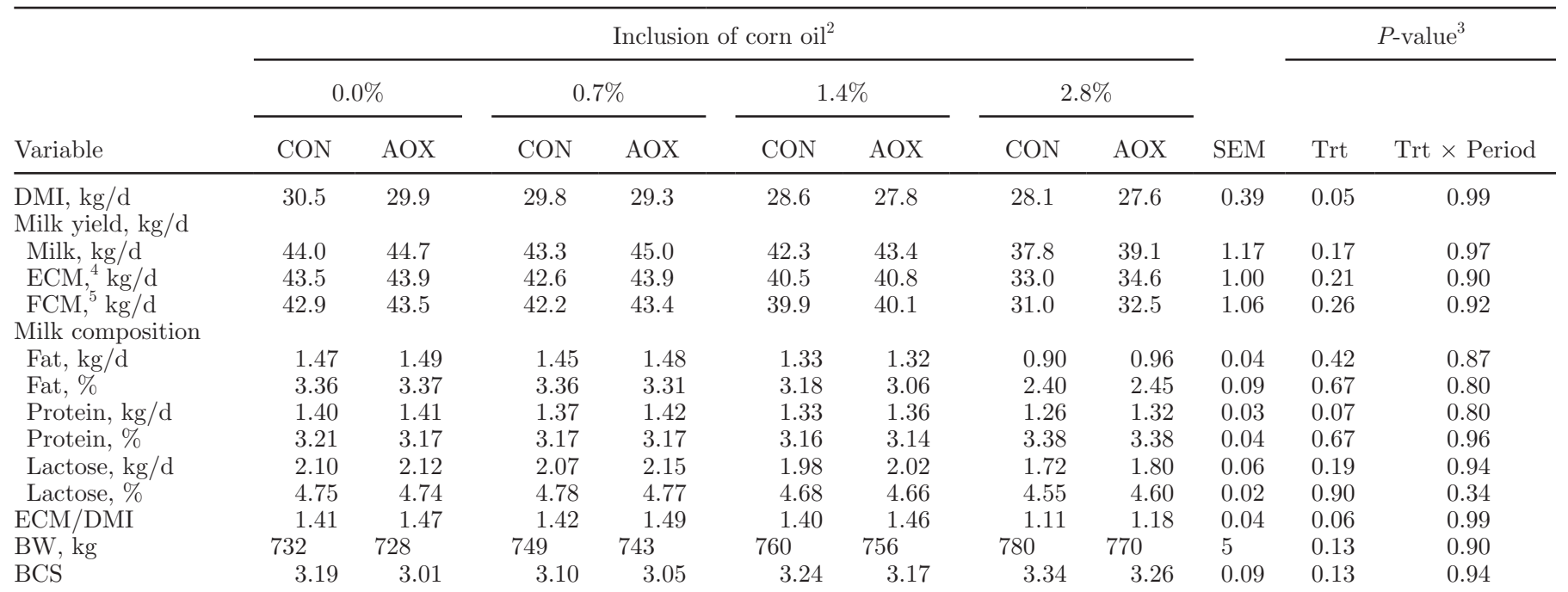

${ }^{1}$ Treatments were either control diet $(\mathrm{CON} ; \mathrm{n}=13 \mathrm{cows})$ or the same diet supplemented with $6.1 \mathrm{~g} / \mathrm{d}$ of synthetic antioxidant (AOX; dry blend of ethoxyquin and propyl gallate, Novus International Inc., St. Charles, MO; $\mathrm{n}=13$ cows).

${ }^{2}$ Corn oil inclusion rate in the diet as \% of diet DM.

${ }^{3} P$-values associated with the main effect of treatment (CON vs. AOX) and interaction between treatment and period (corn oil inclusion, 0.0 , $0.7,1.4$, or $2.8 \% \mathrm{DM})$.

${ }^{4} \mathrm{ECM}=[(0.327 \times \mathrm{kg}$ of milk $)+(12.95 \times \mathrm{kg}$ of milk fat $)+(7.20 \times \mathrm{kg}$ of milk protein $)] ;$ Tyrrell and Reid $(1965)$.

${ }^{5} 3.5 \% \mathrm{FCM}=[(0.4324 \times \mathrm{kg}$ of milk $)+(16.216 \times \mathrm{kg}$ of milk fat $)]$.

and implementation. Because unsaturated FA are toxic to rumen bacteria (Maia et al., 2007), biohydrogenation represents a protective mechanism by converting unsaturated to saturated FA. Altered rumen fermentation can result in shifts from normal biohydrogenation to alternative pathways, producing specific FA intermediates that reduce fat synthesis in the mammary gland (Bauman et al., 2011). If effective in preventing shifts in biohydrogenation and therefore MFD, the incorporation of an antioxidant into a diet may allow for increased use of byproduct feeds that often contain high and variable FA concentrations, allowing for more options when balancing rations. Possible benefits and mode(s) of action of antioxidants in human and animal health have been examined for over $20 \mathrm{yr}$ (Lykkesfeldt and Svendsen, 2007). It was recently proposed that the toxicity of unsaturated FA is due to a metabolic affect rather than disruption of membrane integrity (Maia et al., 2010). Unfortunately, a direct link between dietary antioxidants and biohydrogenation is lacking, although the role of vitamin $\mathrm{E}$ ( $\alpha$-tocopherolquinone) as an endogenous electron donor for biohydrogenation has been known for some time (Hughes and Tove, 1980).

Variation in the nutrient composition of individual feed ingredients was such that we did observe some differences in dietary NDF and starch concentrations across corn oil inclusion periods. Furthermore, the magnitude of difference in total FA concentration between the 0.7 and $1.4 \%$ corn oil inclusions was not as great as expected, although the difference in total FA concentration between 0 and $2.8 \%$ corn oil inclusion was as expected. The difference between observed and expected total FA concentration was a result of reduced 18-carbon unsaturated FA in cottonseed and alfalfa silage during the $1.4 \%$ corn oil period compared with other periods (data not shown). Our experimental diets, even at $2.8 \%$ added corn oil, contained only $5.3 \%$ total FA, a concentration that could potentially be observed on commercial farms. We acknowledge, however, that the FA in corn oil are likely more available in the rumen than the FA present in most other feeds that might contribute to these higher dietary FA concentrations. Although the $0 \%$ corn oil diet contained low dietary FA, adequate NDF and forage NDF, and average levels of moderately fermentable starch, the low milk fat concentration we observed was unexpected. It remains to be determined, therefore, whether we would have observed similar results if cows had started at a higher milk fat concentration.

One limitation of our study is that corn oil inclusion and period effects were confounded, with oil being added at increasing levels in consecutive periods, precluding separation of corn oil and period effects. Recovery from diet-induced MFD can take approximately 2 wk (Rico and Harvatine, 2013). Therefore, to minimize carryover effects and decrease the length of the overall study, we chose to have cows increase RUFAL in consecutive periods rather than allowing cows to recover 
Table 4. Milk FA concentrations of cows fed treatment diets

\begin{tabular}{|c|c|c|c|c|c|c|c|c|c|c|c|}
\hline \multirow[b]{3}{*}{ Variable } & \multicolumn{8}{|c|}{ Inclusion of corn oil ${ }^{2}$} & \multirow[b]{3}{*}{ SEM } & \multicolumn{2}{|c|}{$P$-value ${ }^{3}$} \\
\hline & \multicolumn{2}{|c|}{$0.0 \%$} & \multicolumn{2}{|c|}{$0.7 \%$} & \multicolumn{2}{|c|}{$1.4 \%$} & \multicolumn{2}{|c|}{$2.8 \%$} & & \multirow[b]{2}{*}{ Trt } & \multirow[b]{2}{*}{ Trt $\times$ Period } \\
\hline & $\mathrm{CON}$ & AOX & $\mathrm{CON}$ & AOX & $\mathrm{CON}$ & AOX & $\mathrm{CON}$ & AOX & & & \\
\hline \multicolumn{12}{|c|}{ 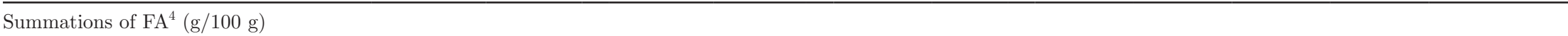 } \\
\hline De novo & 26.6 & 26.2 & 25.8 & 25.3 & 23.2 & 22.6 & 16.5 & 17.0 & 0.59 & 0.56 & 0.71 \\
\hline Mixed & 35.2 & 36.2 & 31.9 & 33.0 & 29.7 & 30.4 & 27.4 & 28.6 & 0.52 & 0.006 & 0.98 \\
\hline \multirow{2}{*}{\multicolumn{12}{|c|}{ Selected individual $\mathrm{FA}^{5}(\mathrm{~g} / 100 \mathrm{~g})$}} \\
\hline & & & & & & & & & & & \\
\hline $4: 0$ & 2.88 & 2.95 & 2.94 & 2.85 & 2.95 & 2.82 & 1.97 & 2.05 & 0.11 & 0.80 & 0.68 \\
\hline $6: 0$ & 2.03 & 2.03 & 2.06 & 1.97 & 1.89 & 1.79 & 1.08 & 1.16 & 0.07 & 0.62 & 0.56 \\
\hline $8: 0$ & 1.25 & 1.23 & 1.27 & 1.20 & 1.09 & 1.03 & 0.57 & 0.62 & 0.05 & 0.44 & 0.49 \\
\hline 10:0 & 3.27 & 3.15 & 3.20 & 3.01 & 2.61 & 2.44 & 1.37 & 1.46 & 0.12 & 0.24 & 0.59 \\
\hline $12: 0$ & 3.94 & 3.78 & 3.75 & 3.58 & 3.05 & 2.87 & 1.90 & 1.96 & 0.11 & 0.15 & 0.61 \\
\hline $14: 0$ & 12.2 & 12.2 & 11.6 & 11.8 & 10.6 & 10.6 & 8.35 & 8.66 & 0.22 & 0.41 & 0.92 \\
\hline $14: 1$ cis-9 & 0.97 & 0.97 & 0.91 & 0.99 & 0.97 & 1.05 & 1.18 & 1.21 & 0.07 & 0.32 & 0.91 \\
\hline $16: 0$ & 33.4 & 34.5 & 30.2 & 31.3 & 28.0 & 28.6 & 25.1 & 26.3 & 0.46 & 0.003 & 0.94 \\
\hline $16: 1$ cis-9 & 1.81 & 1.78 & 1.62 & 1.73 & 1.64 & 1.82 & 2.26 & 2.32 & 0.12 & 0.39 & 0.83 \\
\hline $18: 0$ & 7.84 & 8.07 & 9.00 & 8.64 & 9.78 & 9.16 & 9.67 & 9.71 & 0.30 & 0.41 & 0.48 \\
\hline 18:1 trans -9 & 0.21 & 0.22 & 0.29 & 0.30 & 0.41 & 0.45 & 0.80 & 0.74 & 0.03 & 0.97 & 0.29 \\
\hline $18: 1$ trans -10 & 0.54 & 0.66 & 0.66 & 0.96 & 1.48 & 1.85 & 6.37 & 5.95 & 0.38 & 0.74 & 0.72 \\
\hline 18:1 trans- 11 & 0.80 & 0.70 & 1.22 & 1.21 & 1.79 & 1.68 & 1.66 & 1.79 & 0.11 & 0.78 & 0.70 \\
\hline $18: 1$ cis-9 & 17.3 & 17.2 & 19.0 & 18.8 & 20.8 & 21.2 & 24.1 & 23.2 & 0.40 & 0.50 & 0.39 \\
\hline $18: 1$ cis- 11 & 0.60 & 0.58 & 0.59 & 0.62 & 0.66 & 0.69 & 0.73 & 0.76 & 0.03 & 0.46 & 0.79 \\
\hline $18: 2$ cis- 9, cis- 12 & 2.62 & 2.49 & 2.85 & 2.72 & 3.00 & 2.94 & 3.29 & 3.08 & 0.07 & 0.01 & 0.73 \\
\hline $18: 3$ cis-9,cis-12,cis-15 & 0.34 & 0.32 & 0.34 & 0.33 & 0.32 & 0.32 & 0.33 & 0.30 & 0.007 & 0.004 & 0.54 \\
\hline $18: 2$ cis- 9, trans- 11 & 0.41 & 0.36 & 0.57 & 0.60 & 0.84 & 0.85 & 0.88 & 0.89 & 0.05 & 0.99 & 0.89 \\
\hline 18:2 trans-9,cis-11 & 0.01 & 0.01 & 0.01 & 0.01 & 0.02 & 0.03 & 0.09 & 0.09 & 0.006 & 0.60 & 0.72 \\
\hline $18: 2$ trans -10, cis -12 & $<0.001$ & $<0.001$ & $<0.001$ & $<0.001$ & 0.01 & 0.01 & 0.03 & 0.03 & 0.003 & 0.56 & 0.29 \\
\hline
\end{tabular}

${ }^{1}$ Treatments were either control diet (CON; $\left.\mathrm{n}=13 \mathrm{cows}\right)$ or the same diet supplemented with $6.1 \mathrm{~g} / \mathrm{d}$ of a synthetic antioxidant (AOX; dry blend of ethoxyquin and propyl gallate, Novus International Inc., St. Charles, MO; $\mathrm{n}=13$ cows).

${ }^{2}$ Corn oil inclusion rate in the diet as \% of diet DM.

${ }^{3} P$-values associated with the main effect of treatment (Trt; CON vs. AOX) and interaction between treatment and period (corn oil inclusion, $0.0,0.7,1.4$, or $2.8 \%$ DM).

${ }^{4}$ De novo FA originate from mammary de novo synthesis ( $<16$ carbons), preformed FA originate from extraction from plasma ( $>16$ carbons), and mixed FA originate from both sources $(\mathrm{C} 16: 0+$ cis-9 $\mathrm{C} 16: 1)$.

${ }^{5} \mathrm{~A}$ total of approximately 70 individual FA were quantified and used for calculations (summation by source and concentrations). Only select FA are reported in the table. 
from shifts in rumen biohydrogenation pathways and MFD that occurs with high RUFAL diets. This allowed us to determine the main effect of our AOX treatment when supplemented to diets with increasing levels of corn oil (RUFAL) across the treatment periods.

As expected, increasing dietary corn oil concentration across periods decreased DMI, milk yield, milk fat concentration and yield, and feed efficiency. However, at the concentration tested, the synthetic antioxidant used in the current study did not effectively reduce the extent of MFD when increasing concentrations of corn oil were added to the diet. Interestingly, studies evaluating the effects of feeding a dietary antioxidant have obtained mixed results. In some studies that supplemented vitamin $\mathrm{E}$ at a high dietary concentration, an increase in milk fat yield occurred with no differences in yield of milk or milk protein (Charmley and Nicholson, 1994; Focant et al., 1998; Pottier et al., 2006), suggesting that vitamin $\mathrm{E}$ might prevent the trans-10 shift during biohydrogenation. However, results from studies designed to directly examine the effect of vitamin E supplementation on overcoming MFD offer no support for a role of vitamin E in mitigating MFD (O'Donnell-Megaro et al., 2012; Zened et al., 2012). A synthetic dietary antioxidant supplemented during the dry period and early lactation showed a tendency for increased fat-corrected milk, possibly because the risk of oxidative stress is high in early lactation (Wang et al., 2010). However, He and Armentano (2011) supplemented a synthetic antioxidant while feeding high amounts of unsaturated FA to cows in mid- to late-lactation and observed no effect of antioxidant supplementation on milk or milk fat yield. On the other hand, Vázquez-Añón et al. (2008) reported improved milk fat yield when a synthetic antioxidant was supplemented with either oxidized or fresh soybean oil at $2.0 \%$ of diet DM to cows in mid- to late-lactation. We recently reported that when the same synthetic antioxidant as used by He and Armentano (2011) and Vázquez-Añón et al. (2008) was supplemented in a diet containing high amounts of dried distillers grains (designed to cause MFD), it tended to increase milk fat concentration but not yield (Boerman et al., 2014). In the latter study, the synthetic antioxidant was added to the diet at the time of the MFD challenge. We proposed that the antioxidant might need to be added to the diet several days before feeding an increased RUFAL diet to stabilize the rumen environment before the MFD challenge. Therefore, in our current study, we evaluated the effect of incrementally increasing RUFAL after the synthetic antioxidant had been included in the diet for $3 \mathrm{wk}$ before the first RUFAL challenge. Under the dietary situations in the current study, the synthetic antioxidant was not effective in minimizing the MFD induced by increased corn oil. Reasons for the varia- tion in responses across studies with both vitamin $\mathrm{E}$ and synthetic antioxidants remain to be determined. In particular, it would be useful to know in what situations such antioxidants may or may not mitigate an MFD challenge. In the current study, DMI was lower for the AOX treatment, which contradicts the results of Vázquez-Añón et al. (2008) in first-lactation cows in mid and late lactation but is in agreement with the results of Wang et al. (2010) in early lactation cows.

Our study implemented dietary corn oil challenges to test the effects of AOX on biohydrogenation patterns and the alleviation of MFD. Although milk FA composition is not a direct measurement of biohydrogenation, increased concentrations of trans-10 C18:1, trans-10,cis-12 C18:2, and trans-9,cis-11 C18:2 in milk fat are indicators of altered rumen biohydrogenation (Bauman et al., 2011). Pottier et al. (2006) reported a $16 \%$ increase in milk fat yield, which was associated with a $\sim 45 \%$ decrease in the concentration of trans-10 C18:1 in milk fat when vitamin $\mathrm{E}$ was supplemented to cows fed $\sim 1 \%$ DM linseed oil. However, this potential maintenance of normal biohydrogenation pathways was only evident when vitamin $\mathrm{E}$ was incorporated in the diet simultaneously with the linseed oil; once the trans-10 shift had occurred, the subsequent addition of vitamin $\mathrm{E}$ was no longer able to counteract this process (Pottier et al., 2006). In our study, the concentrations of trans-10 C18:1, trans-10, cis-12 C18:2, and trans-9, cis-11 C18:2 in milk FA increased with increasing RUFAL. We did not, however, observe shifts in these specific FA or other C18:1 isomers as a result of AOX treatment, demonstrating that, under the conditions of our study, the synthetic antioxidant was not effective in shifting (or maintaining normal) ruminal biohydrogenation. This is in agreement with recent studies that directly examined the effect of vitamin E supplementation on MFD that offer no support for a role of vitamin $\mathrm{E}$ in maintaining normal biohydrogenation pathways and mitigating MFD (O'Donnell-Megaro et al., 2012; Zened et al., 2012). Interestingly, we observed a reduction in the concentration of cis-9,cis-12 C18:2 in milk in the current study with AOX, in contrast to a recent study when a similar synthetic antioxidant was fed in combination with a high dietary concentration of distillers grains and where the cis-9,cis-12 C18:2 concentration of milk was elevated (Boerman et al., 2014). Possible reasons for these differences between studies are unknown.

\section{CONCLUSIONS}

This experiment examined the effect of a synthetic dietary antioxidant on DMI and yields of milk and milk components. We hypothesized that feeding the synthetic antioxidant would counteract the negative 
effects of increasing RUFAL on milk fat. To test this hypothesis, we added corn oil in consecutive experimental periods to increase RUFAL. Biohydrogenation intermediates associated with decreased milk fat synthesis in the mammary gland were elevated as milk fat yield decreased. Supplementation with AOX, however, did not overcome the dietary-induced MFD caused by increased RUFAL.

\section{ACKNOWLEDGMENTS}

We acknowledge Novus International Inc. (St. Charles, MO) for financial support of this research. We also thank G. Zanton (Novus International Inc.), T. Hillier, K. E. DeLand, D. G. Main, J. E. Rico, and J. S. Liesman (all in the Department of Animal Science, Michigan State University), and the staff of the Michigan State University Dairy Cattle Field Laboratory for their assistance in this experiment.

\section{REFERENCES}

AOAC. 1990. Official Methods of Analysis. 15th ed. Association of Official Analytical Chemists (AOAC), Arlington, VA.

AOAC International. 2000. Official Methods of Analysis. 17th ed. AOAC International, Arlington, VA.

Bauman, D. E., and C. L. Davis. 1974. Biosynthesis of milk fat. Lactation: A Comprehensive Treatise. Vol. 2. B. L. Larson and V. R. Smith, ed. Academic Press, London, UK.

Bauman, D. E., K. J. Harvatine, and A. L. Lock. 2011. Nutrigenomics, rumen-derived bioactive fatty acids, and the regulation of milk fat synthesis. Annu. Rev. Nutr. 31:299-319.

Baumgard, L. H., J. K. Sangster, and D. E. Bauman. 2001. Milk fat synthesis in dairy cows is progressively reduced by increasing supplemental amounts of trans-10, cis-12 conjugated linoleic acid (CLA). J. Nutr. 131:1764-1769.

Boerman, J. P., C. L. Preseault, J. Kraft, H. M. Dann, and A. L. Lock. 2014. Short communication: Effect of antioxidant supplementation on milk production, milk fat synthesis, and milk fatty acids in dairy cows fed a diet designed to cause milk fat depression. J. Dairy Sci. 97:1077-1081.

Charmley, E., and J. W. G. Nicholson. 1994. Influence of dietary fat source on oxidative stability and fatty acid composition of milk from cows receiving a low or high level of dietary vitamin E. Can. J. Anim. Sci. 74:657-664.

Focant, M., E. Mignolet, M. Marique, F. Clabots, T. Breyne, D. Dalemans, and Y. Larondelle. 1998. The effect of vitamin E supplementation of cow dies containing rapeseed and linseed on the prevention of milk fat oxidation. J. Dairy Sci. 81:1095-1101.

Hall, M. B. 2009. Analysis of starch, including maltooligosacchardies, in animal feeds: A comparison of methods and a recommended method for AOAC collaborative study. J. AOAC Int. 92:42-49.

He, M., and L. E. Armentano. 2011. Effect of fatty acid profile in vegetable oils and antioxidant supplementation on dairy cattle performance and milk fat depression. J. Dairy Sci. 94:2481-2491.

Hughes, P. E., and S. B. Tove. 1980. Identification of an endogenous electron donor for biohydrogenation as alpha-tocopherolquinol. J. Biol. Chem. 255:4447-4452.

Lock, A. L., C. L. Preseault, J. E. Rico, K. E. DeLand, and M. S. Allen. 2013. Feeding a C16:0-enriched fat supplement increased the yield of milk fat and improved conversion of feed to milk. J. Dairy Sci. 96:6650-6659.

Lock, A. L., C. Tyburczy, D. A. Dwyer, K. J. Harvatine, F. Destaillats, Z. Mouloungui, L. Candy, and D. E. Bauman. 2007. Trans-10 octadecenoic acid does not reduce milk fat synthesis in dairy cows. J. Nutr. 137:71-76.
Loor, J. J., A. Ferlay, A. Ollier, M. Doreau, and Y. Chilliard. 2005. Relationship among trans and conjugated fatty acids and bovine milk fat yield due to dietary concentrate and linseed oil. J. Dairy Sci. 88:726-740.

Lykkesfeldt, J., and O. Svendsen. 2007. Oxidants and antioxidants in disease: Oxidative stress in farm animals. Vet. J. 173:502-511.

Maia, M. R. G., L. C. Chaudhary, C. S. Bestwick, A. J. Richardson, N. Mckain, T. R. Larson, I. A. Graham, and R. J. Wallace. 2010. Toxicity of unsaturated fatty acids to the biohydrogenating ruminal bacterium, Butyrivibrio fibrisolvens. BMC Microbiol. 10:52.

Maia, M. R. G., L. C. Chaudhary, L. Figueres, and R. J. Wallace. 2007. Metabolism of polyunsaturated fatty acids and their toxicity to the microflora of the rumen. Antonie Van Leeuwenhoek 91:303-314.

NRC. 2001. Nutrient Requirements of Dairy Cattle. 7th rev. ed. National Acad. Sci., Washington, DC.

O’Donnell-Megaro, A. M., J. L. Capper, W. P. Weiss, and D. E. Bauman. 2012. Effect of linoleic acid and dietary vitamin E supplementation on sustained conjugated linoleic acid production in milk fat from dairy cows. J. Dairy Sci. 95:7299-7307.

Perfield, J. W. II, A. L. Lock, J. M. Griinari, A. Sæbø, P. Delmonte, D. A. Dwyer, and D. E. Bauman. 2007. Trans-9, cis-11 conjugated linoleic acid (CLA) reduces milk fat synthesis in lactating dairy cows. J. Dairy Sci. 90:2211-2218.

Piantoni, P., A. L. Lock, and M. S. Allen. 2013. Palmitic acid increased yields of milk and milk fat and nutrient digestibility across production level of lactating cows. J. Dairy Sci. 96:7143-7154.

Pottier, J., M. Focant, C. Debier, G. De Buysser, C. Goffe, E. Mignolet, E. Froidmont, and Y. Larondelle. 2006. Effect of dietary vitamin $\mathrm{E}$ on rumen biohydrogenation pathways and milk fat depression in dairy cows fed high-fat diets. J. Dairy Sci. 89:685-692.

Rico, D. E., and K. J. Harvatine. 2013. Induction of and recovery from milk fat depression occurs progressively in dairy cows switched between diets that differ in fiber and oil concentration. J. Dairy Sci. 96:6621-6630.

Sæbø, A., P. Sæbø, J. M. Griinari, and K. J. Shingfield. 2005. Effect of abomasal infusions of geometric isomers of 10,12 conjugated linoleic acid on milk fat synthesis in dairy cows. Lipids 40:823-832.

Shingfield, K. J., C. K. Reynolds, G. Hervàs, J. M. Griinari, A. S. Grandison, and D. E. Beever. 2006. Examination of the persistency of milk fatty acid composition responses to fish oil and sunflower oil in the diet of dairy cows. J. Dairy Sci. 89:714-732.

Tyburczy, C., P. Delmonte, A.-R. Fardin Kia, M. M. Mossoba, J. K. G. Kramer, and J. I. Rader. 2012. Profile of trans fatty acids (FAs) including trans polyunsaturated FAs in representative fast food samples. J. Agric. Food Chem. 60:4567-4577.

Tyrrell, H. F., and J. T. Reid. 1965. Prediction of the energy value of the milk. J. Dairy Sci. 48:1215-1223.

Ulberth, F., and F. Schrammel. 1995. Accurate quantitation of short-, medium-, and long-chain fatty acid methyl esters by split-injection capillary gas-liquid chromatography. J. Chromatogr. A 704:455463.

Van Soest, P. J., J. B. Roberson, and B. A. Lewis. 1991. Methods for dietary fiber, neutral detergent fiber, and nonstarch polysaccharides in relation to animal nutrition. J. Dairy Sci. 74:3583-3597.

Vázquez-Añón, M., J. Nocek, G. Bowman, T. Hampton, C. Atwell, P. Vazquez, and T. Jenkins. 2008. Effect of feeding a dietary antioxidant in diets with oxidized fat on lactation performance and antioxidant status of the cow. J. Dairy Sci. 91:3165-3172.

Wang, Y. M., J. H. Wang, C. Wang, J. K. Wang, B. Chen, J. X. Liu, H. Cao, and F. C. Guo. 2010. Effect of dietary antioxidant and energy density on performance and anti-oxidative status of transition cows. Asian-australas. J. Anim. Sci. 23:1299-1307.

Wildman, E. E., G. M. Jones, P. E. Wagner, and R. L. Bowman. 1982. A dairy cow body condition scoring system and its relationship to selected production characteristics. J. Dairy Sci. 65:495-501.

Zened, A., A. Troegeler-Meynadier, T. Najar, and F. Enjalbert. 2012. Effects of oil and natural or synthetic vitamin $\mathrm{E}$ on ruminal and milk fatty acid profiles in cows receiving a high-starch diet. J. Dairy Sci. 95:5916-5926. 